\title{
Endoscopic lung volume reduction with coils
}

\author{
M J Vorster, ${ }^{1} \mathrm{MB}$ ChB, MRCP (UK), MMed (Int), FCP (SA); J Theron, ${ }^{1,2} \mathrm{MB}$ ChB, MMed (Int), Cert Pulm (SA); \\ K Dheda, ${ }^{3} \mathrm{MB}$ ChB, FCP (SA), FCCP, PhD, FRCP (UK); J W Bruwer, ${ }^{4} \mathrm{MB}$ ChB, MMed (Int), FCP (SA), Cert Pulm (SA); \\ B W Allwood, ${ }^{1} \mathrm{MB} \mathrm{ChB}, \mathrm{FCP}(\mathrm{SA}), \mathrm{MPH}$, Cert Pulm (SA), PhD; F von Groote-Bidlingmaier, ${ }^{1} \mathrm{MD}$; \\ C F N Koegelenberg, ${ }^{1}$ MB ChB, MMed (Int), FCP (SA), FRCP (UK), Cert Pulm (SA), PhD \\ ${ }^{1}$ Division of Pulmonology, Department of Medicine, Stellenbosch University and Tygerberg Academic Hospital, Cape Town, South Africa \\ ${ }^{2}$ Panorama Heart and Lung Unit, Panorama Mediclinic, Cape Town, South Africa \\ ${ }^{3}$ Division of Pulmonology, Department of Medicine, University of Cape Town and Groote Schuur Hospital, Cape Town, South Africa \\ ${ }^{4}$ Windhoek Mediclinic, Namibia
}

Corresponding author: MJ Vorster(mvorster@sun.ac.za)

The use of endoscopic lung volume reduction (ELVR) as a minimally invasive procedure with significantly lower morbidity and mortality than surgery, is fast becoming a new treatment modality for a select group of patients with severe emphysema. Lung volume reduction can be achieved either by surgery (LVRS) or the use of endoscopic techniques. Although LVRS offers survival benefit and increased exercise capacity in selected patients, this comes at a price with significant associated morbidity and mortality. The use of endoscopic lung volume reduction (ELVR) aims to reduce the risks and costs of surgery with comparable physiological benefits. Current evidence suggests that not all classes and phenotypes of emphysema will benefit from lung volume reduction, and that individual techniques may benefit different subgroups of patients. It therefore remains paramount that a systematic approach is followed and selection criteria are met, given the high costs and potential complications related to both LVRS and ELVR.

S Afr Resp J 2015;21(2):30-32. DOI:10.7196/sarj.8442

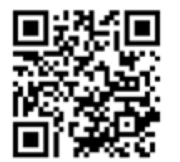

Lung volume reduction surgery (LVRS) has been shown to improve clinical and functional status and mortality in the subgroup of patients with predominant upperlobe emphysema and low exercise capacity. ${ }^{[1]}$ LVRS has been marked by a significant 90 -day mortality rate in experienced hands (4\%) as well as post-procedural morbidity. ${ }^{[2]}$ Interest has grown in the development of a minimally invasive way to reduce lung volume, which can minimise morbidity and mortality. Endoscopic lung volume reduction (ELVR) is currently used as an alternative intervention, and there is a growing body of evidence that certain well-defined subgroups of patients with advanced emphysema may show significant benefit from ELVR. There are certain selection criteria that should be met and a systematic approach is recommended. ${ }^{[3]}$ Several techniques are currently available, but only a few modalities have been properly evaluated in prospective trials. Valves have been commercially available for some time in South Africa, though coils were only recently introduced to South Africa, with the first implantations performed in September 2014. This review gives an overview of the rationale, appropriate candidates, technical aspects and current evidence for the use of coils in achieving ELVR.

\section{The rationale for lung volume reduction}

ELVR, in principle, aims to achieve atelectasis of the targeted region, thereby reducing its volume and redirecting airflow to less affected regions. ${ }^{[3]}$ Dynamic hyperinflation decreases and diaphragmatic and chest wall mechanics improve. The remaining lung tissue has better elastic properties, which then restores the outward radial pull on the small airways, thereby increasing expiratory airflow. Reducing inhomogeneity of regional ventilation and perfusion improves ventilation/perfusion matching. Endobronchial coils, in theory, retension the airway network to mechanically increase elastic recoil in the emphysematous lungs and tether open airways, thereby preventing airway collapse. ${ }^{[4]}$

\section{Caveats}

Bronchial blocking devices have been shown to be less effective in homogeneous emphysema or in cases where significant collateral ventilation is present. ${ }^{[3,5]}$ The degree of heterogeneity is generally determined from chest computed tomography scanning, either by visual inspection or with the aid of specifically designed software. Collateral ventilation is a normal physiological phenomenon in some individuals. Significant interlobar collateral ventilation prevents atelectasis and thereby subverts the deflating effect of endobronchial blocking devices. Interlobar collateral ventilation is considered to be present if high-resolution computed tomography (HRCT) scans show incomplete fissures. ${ }^{[3]}$ Most European centres, however, currently use an endobronchial catheter system (Chartis Pulmonary Assessment System, Pulmonx Inc., USA) to evaluate the presence and percentage of interlobar collateral ventilation. A balloon catheter, connected to a console, is inserted via a bronchoscope into an airway and then inflated to occlude the airway. ${ }^{[6]}$ A near constant rate of expiratory airflow, measured at the occluded airway, is seen in cases with collateral ventilation, whereas a steady reduction in flow is observed in the absence of collateral ventilation. A recent study found that quantitative HRCT 
achieved comparable results to the Chartis system for the use as a guide to effectively assess collateral ventilation and to select patients for valve-based ELVR procedures. ${ }^{[7]}$ The evidence suggests that if the fissures are $<75 \%$ intact, the Chartis system evaluation should not be performed, as collateral ventilation is always present, whereas with fissure integrity $>90 \%$ the Chartis evaluation is always practically superfluous, as collateral ventilation is practically never present. The Chartis system is therefore of value in cases where collateral ventilation is questionable, as predicted by HRCT reporting 75 - 90\% fissural integrity.

With endobronchial coils the evidence suggests that appropriate candidates with both heterogeneous and homogeneous emphysema could experience clinically significant benefit from ELVR using coils, irrespective of collateral ventilation or complete lobar collapse. The evidence for this is discussed below.

\section{Technical aspects}

Coils (RePneu, BTG Inc., USA) are nitinol devices (Fig. 1) that have been preformed to a shape that results in parenchymal retraction after deployment. ${ }^{[4]}$ The device is currently available in three lengths $(100,125$ and $150 \mathrm{~mm}$ ) to accommodate different sized airways. The coils are implanted via a flexible bronchoscope under general anaesthesia or conscious sedation and fluoroscopic guidance using a proprietary delivery system. The airway in the selected segment is identified with a low-stiffness guidewire (under fluoroscopy), after which a catheter is passed over the guidewire and the length of the airway is measured. The guidewire is then removed and a straightened coil is introduced into the distal end of the catheter with a grasper, after which the catheter is removed while the proximal end of the coil is initially advanced and then released, assuming its preformed shape.

\section{Evidence}

A pilot study by Herth et al. ${ }^{[4]}$ found endoscopic lung volume reduction with coils to be safe and feasible. In a subsequent study by Slebos et al., ${ }^{[8]} 18$ patients with severe heterogeneous disease showed significant improvement in functional parameters. After 6 months, the St George's Respiratory Questionnaire (SGRQ) improved by mean (standard deviation (SD)) 14.9 (12.1) points (with 11 patients improving by $>4$ points), the forced respiratory volume in 1 second $\left(\mathrm{FEV}_{1}\right)$ by a mean of $14.9 \%$, forced vital capacity (FVC) by $13.4 \%$, residual volume (RV) by a mean of $11.4 \%$ and 6-minute walk distance (6MWD) by $84.4 \mathrm{~m}$.

In a multicentre study by Shah et al., ${ }^{[9]}$ 47 patients with severe emphysema (both heterogeneous and homogeneous disease) were randomly allocated in a 1:1 ratio to either treatment with coils (treatment group, $n=23$ ) or best medical care (usual care group, $n=24$ ). The primary endpoint was the difference in response in SGRQ between treatment and usual care groups at 90 days after final treatment (by intention-to-treat analysis). The SGRQ response at 90 days after final treatment was greater in the treatment group than in the usual care group (between-group difference from baseline -8.36 points ( $95 \%$ confidence interval -16.24 to -0.47$) ; p=0.04) .{ }^{[9]}$ In a larger multicentre study that initially focused on mostly heterogeneous disease, 60 patients were treated with coils (55 bilateral), ${ }^{[5]}$ again looking at improvement in SGRQ but with a longer follow-up (6 months) and comparing that with baseline ( $\triangle \mathrm{SGRQ})$. At 6 and 12 months, respectively, $\triangle \mathrm{SGRQ}$ was a mean $(\mathrm{SD})$ of -12.1 (12.9) points and -11.1 (13.3) points, $\Delta 6 \mathrm{MWD}$ was $+29.7(74.1) \mathrm{m}+51.4(76) \mathrm{m}$, $\Delta \mathrm{FEV}_{1}$ was $+0.11(0.20) \mathrm{L}$ and $+0.11(0.30) \mathrm{L}$, and $\triangle \mathrm{RV}$ was $-0.65(0.90) \mathrm{L}$ and -0.71 (0.81) L (all $p<0.01) \cdot{ }^{[5]}$ In both the studies there was a significant improvement in $\mathrm{FEV}_{1}$ with almost $60 \%$ of treated patients experiencing

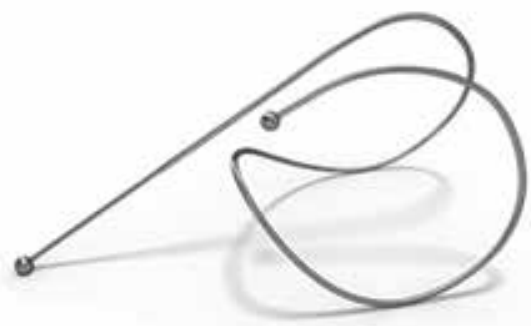

Fig. 1. An endobronchial (RePneu) coil.

Table 1. General indications and contraindications for endoscopic lung volume reduction with endobronchial and intrabronchial coils in patients with stable emphysema

Indication

40 - 75 yr

Dyspnoea despite maximal medical therapy and pulmonary rehabilitation

$\mathrm{FEV}_{1} 15-45 \%$

Hyperinflation with TLC $>100 \%$ and RV $>150-175 \%$

$\mathrm{PaCO}_{2}<6.7 \mathrm{kPa}(50 \mathrm{mmHg})$

$\mathrm{PaO}_{2}>6 \mathrm{kPa}$ (45 mmHg) while breathing ambient air

$6 \mathrm{MWD} \geq 140 \mathrm{~m}$ (post-rehabilitation)

Contraindications

$>75 \%$ parenchymal destruction on HRCT

Current smoking (previous 6 months)

DLCO $<20 \%$

Giant bullae ( $>1 / 3$ of hemithorax)

$\alpha 1$-antitrypsin deficiency

Previous thoracotomy, pleurodesis or chest wall deformity

Excessive sputum

Severe pulmonary hypertension $(>50 \mathrm{mmHg})$

Active infection

Unstable cardiac conditions

Significant pleural or interstitial changes on HRCT

Any type of antiplatelet or anticoagulant therapy that cannot be stopped for 7 days prior to procedure

TLC = total lung capacity; $\mathrm{PaCO}_{2}=$ partial pressure of carbon dioxide in the arterial blood; $\mathrm{PaO}_{2}=$ partial pressure of oxygen in the arterial blood; DLCO = diffusing capacity. 
a $>10 \%$ improvement in $\mathrm{FEV}_{1}$ in the initial study and at 6 months, $48.0 \%$ of patients were found to have $\mathrm{a} \geq 12 \%$ increase in $\mathrm{FEV}_{1}$ in the latter group. Post hoc analyses showed significant responses for SGRQ, $6 \mathrm{MWD}$ and RV in patients with both heterogeneous and homogeneous emphysema. Serious adverse events that were observed within 30 days of treatment included 7 exacerbations (6.1\%), 6 pneumonias (5.2\%), 4 pneumothoraces $(3.5 \%)$ and 1 haemoptysis $(0.9 \%),{ }^{[5]}$ though no between-group difference in serious adverse events was observed when comparing with the control group. ${ }^{[9]}$

A recent open-label study focused exclusively on the use of coils in homogeneous emphysema. ${ }^{[10]}$ Ten patients with severe chronic obstructive pulmonary disease and hyperinflation were treated with a median of 11 (range 10 - 12) coils in each lung. At 6 months, 6MWD improved from 289 to $350 \mathrm{~m}$ ( $p=0.005$ ); FVC from 2.17 to $2.55 \mathrm{~L}$ ( $p=0.047)$; RV from 5.04 to $4.44 \mathrm{~L}(p=0.007)$ and SGRQ decreased from 63 to 48 points $(p=0.028)$. Two exacerbations and one small pneumothorax were recorded as serious adverse events. ${ }^{[10]}$

Hartman et al. ${ }^{[11]}$ recently reported their 3-year follow-up data of 38 patients who underwent ELVR using coils. The data showed that the coil treatment was safe, with no late pneumothoraces, coil migrations or unexpected adverse events. Although clinical benefit gradually declined over time, at 3 years post-treatment around $50 \%$ of the patients maintained improvement in 6MWD, SGRQ and dyspnoea scores. ${ }^{[1]}$

Current evidence would therefore suggest that not all classes and phenotypes of emphysema would benefit from ELVR, and that each technique appears to provide greater benefit to specific subgroups of patients. ${ }^{[3]}$ Appropriate candidates with both heterogeneous and homogeneous emphysema could experience clinically significant benefit from ELVR using coils, irrespective of collateral ventilation or complete lobar collapse.

\section{Practical aspects}

Generally speaking, patients with a high degree of hyperinflation with relatively preserved lung parenchyma are more likely to benefit from ELVR with bilateral coils, starting with the most affected side (irrespective of the collateral ventilation and heterogeneity of the disease), ${ }^{[5,10]}$ whereas patients with heterogeneous disease, no collateral circulation and a low baseline perfusion (on ventilation: perfusion scanning) benefit from unilateral therapy with the goal to achieve complete lobar collapse. Only endoscopic valves and coils are currently commercially available in South Africa, and only a few centres currently have the capacity to properly evaluate prospective candidates and potentially offer the ELVR to appropriate cases. The high cost of these interventions makes careful patient selection imperative to prevent wasteful expenditure and insertion in patients unlikely to gain clinical benefit. An ongoing study in France is likely to soon provide information on the cost-effectiveness of ELVR with coils compared with other strategies. ${ }^{[12]}$
The general indications and contraindications for the endoscopic lung volume reduction with endobronchial and intrabronchial coils in patients with stable emphysema are summarised in Table 1 . The Assembly on Interventional Pulmonology of the South African Thoracic Society are currently in the process of finalising a national guideline for the practical use of all devices related to ELVR, including the formal evaluation process. This statement will be published online within the next month.

\section{Conclusions}

Current evidence suggests that in well-defined subgroups of patients with severe emphysema, ELVR with coils may be of benefit. A well-structured, evidence-based approach to ELVR, including initial screening and subsequent referral to a specialised centre, is important to ensure against inappropriate use of devices, which may be both wasteful and harmful.

Patients with a high degree of hyperinflation and relatively preserved lung parenchyma are more likely to benefit from ELVR using bilateral coils, irrespective of the collateral circulation and heterogeneity of the disease. Moreover, there are currently numerous ongoing trials, and suggested approaches are likely to be refined during the next decade.

\section{References}

1. Fishman A, Martinez F, Naunheim K, et al. A randomized trial comparing lungvolume-reduction surgery with medical therapy for severe emphysema. N Engl J Med 2003;348(21):2059-2073. [http://dx.doi.org/10.1056/NEJMoa030287]

2. Yusen RD, Lefrak SS, Gierada DS, et al. A prospective evaluation of lung volume reduction surgery in 200 consecutive patients. Chest 2003;123(4):1026-1037.

3. Gasparini S, Zuccatosta L, Bonifazi M, Bolliger CT. Bronchoscopic treatment of emphysema: State of the art. Respiration 2012;84(3):250-263. [http://dx.doi.org/10.1159/000341171]

4. Herth FJ, Eberhard R, Gompelmann D, Slebos DJ, Ernst A. Bronchoscopic lung volume reduction with a dedicated coil: A clinical pilot study. Ther Adv Respir Dis 2010;4(4):225-231. [http://dx.doi.org/10.1177/1753465810368553]

5. Deslee G, Klooster K, Hetzel M, et al. Lung volume reduction coil treatment for patients with severe emphysema: A European multicentre trial. Thorax 2014;69(11):980-986. [http://dx.doi.org/10.1136/thoraxjnl-2014-205221]

6. Herth FJ, Noppen M, Valipour A, et al. Efficacy predictors of lung volume reduction with Zephyr valves in a European cohort. Eur Respir J 2012;39(6):1334-1342. [http:// dx.doi.org/10.1183/09031936.00161611]

7. Schuhmann M, Raffy P, Yin Y, et al. Computed tomography predictors of response to endobronchial valve lung reduction treatment: Comparison with Chartis. Am J Respir Crit Care Med 2015;191(7):767-774. [http://dx.doi.org/10.1164/rccm.201407-1205OC]

8. Slebos DJ, Klooster K, Ernst A, Herth FJ, Kerstjens HA. Bronchoscopic lung volume reduction coil treatment of patients with severe heterogeneous emphysema. Chest 2012;142(3):574-582. [http://dx.doi.org/10.1378/chest.11-0730]

9. Shah PL, Zoumot Z, Singh S, et al. Endobronchial coils for the treatment of severe emphysema with hyperinflation (RESET): A randomised controlled trial. Lancet Respir Med 2013;1(3):233-240. [http://dx.doi.org/10.1016/S2213-2600(13)70047-X]

10. Klooster K, ten Hacken NH, Franz I, Kerstjens HA, van Rikxoort EM, Slebos DJ. Lung volume reduction coil treatment in chronic obstructive pulmonary disease patients with homogeneous emphysema: A prospective feasibility trial. Respiration 2014;88(2):116-125. [http://dx.doi.org/10.1159/000362522]

11. Hartman JE, Klooster K, Gortzak K, ten Hacken NH, Slebos DJ. Long-term follow-up after bronchoscopic lung volume reduction treatment with coils in patients with severe emphysema. Respirology 2015;20(2):319-326. [http://dx.doi.org/10.1111/resp.12435]

12. Deslee G, Barbe C, Bourdin A, et al. [Cost-effectiveness of lung volume reduction coil treatment in emphysema: STIC REVOLENS]. Rev Mal Respir 2012;29(9):1157-1164. [http://dx.doi.org/10.1016/j.rmr.2012.09.010] 